\title{
A DOUBTER'S GUIDE TO LAW AND NATURAL RigHTS
}

\author{
Dr James Allan*
}

The assertion that there are no independent moral values which transcend the view of an individual, or the society in which he or she lives, may cause consternation to many. Indeed it has been argued that it will turn the liberal western legal tradition on its head by removing the foundation for the rights on which that tradition is built. James Allan in this article suggests that such consternation is misplaced. While an objective moral reality is denied, he accepts the existence of an objective physical world. From this premise he reasons that certain courses of conduct will have certain consequences which, by human nature rather than moral precept, will be desirable or undesirable. It is therefore unlikely that the status quo need be changed to take account of the possibility of moral scepticism. The author proceeds to argue that if the fiction of moral realism were exposed it is likely that the position of tolerance widely adopted in the West would be able to be better defended. He concludes that the Western legal tradition, its commitment to tolerance and the existence of rule based rights would be preserved and enhanced by an acceptance of moral scepticism.

\section{IS THE RIGHT ROAD WHOLLY LOST AND GONE? ${ }^{1}$}

It may be that "the Western legal tradition has always been dependent... on belief in the existence of a body of law beyond the law of the highest political authority, once called divine law, then natural law, and recently human rights." If so, our western legal tradition may now be in the throws of a crisis "greater than any other in its history, one that some believe has brought it virtually to an end. ${ }^{\prime 3}$ In other words, some people fear the effects of

* Senior Lecturer, Faculty of Law, University of Otago.

1 The reference is to the first stanza of canto I of Dante's Comedy, Part I The Inferno:

Midway this way of life we're bound upon,

I woke to find myself in a dark wood,

Where the right road was wholly lost and gone.

(Penguin Books, Harmondsworth, Middlesex, 1949) translated by D L Sayers.

2 H Berman, Law and Revolution (Harvard University Press, Cambridge Mass, 1983), 45.

3 Above n 2, 1 . See also the Preface. 
any scepticism that goes so far as to question the existence of an over-arching, invisible body of divine or natural or human rights. They fear that such questioning, such doubt, ultimately undermines the foundations on which our legal systems are reared. In this paper I shall argue that such a fear is unfounded. Scepticism might seem to pose a potential challenge to law, in particular to law's effectiveness as a unifying social force in constraining conduct, but that appearance is misleading.

In what follows I shall consider certain sceptical claims, their implications, and whether, in fact, this scepticism does indeed pose a threat or challenge to law. Such a consideration best begins with an examination of scepticism itself.

\section{DUBITO ERGO?}

Many aspects of law, the "purposeful enterprise", "that of subjecting human conduct to the guidance and control of general rules", ${ }^{5}$ are open to question. Are law's rules created, evolved or discovered? Do the rules rest on something more than human (conscious or unconscious) engineering? If made, are the rules made apolitically? Are they interpreted apolitically? Is there more to law than just the rules? Are rules less indeterminate than other, non-rule standards? Are the other, non-rule standards created, evolved, discovered or, perhaps, reasoned to?

In a similar vein, there are many today who question whether there are right answers to questions of interpretation. Others wonder whether rules are of benefit in the task of living together in groups and whether humans might not be better off without them. Others still assert that the perception of rules' neutrality serves only to sustain the elite position of some select few in the social group (whether the select few be aware of this or not). And of course there are plenty of people today who ask where the power and authority to make rules and to interpret rules should lie. There is even the often heard demand that this power be limited by some set of enunciated, general (and so usually indeterminate, vague and amorphous) standards, preferably of emotive and rhetorical appeal.

Such questions and concerns could continue, but this is a fair sampling. Each, in its own way, casts doubt on the benefit of law as manifested in the Western legal tradition. If a sceptic be one who doubts the truth of what most others accept, then clearly scepticism about law is a very broad church indeed. Let me circumscribe the membership by focusing firstly not on law at all but on morality.

Moral scepticism is the view that values-right and wrong, good and bad, social norms-are tied to nothing other than the contingent and observably varying responses of

4 L Fuller, The Morality of Law (Yale University Press, New Haven Conn, Revised Edition, 1969) 145.

5 Above n 4, 146. 
human beings. Mind-independent values, in short, do not exist. Nor is there any logical connection or relation between humans and values. The relation depends, says the moral sceptic, on the way humans happen to be constructed, ${ }^{6}$ which could conceivably have been otherwise. Even in terms of how we have been constructed though, experience shows there to be little if any consensus (let alone unanimity) over time, place, culture or rank about valuing. At most it would seem that in some few very general areas (eg revulsion at the prospect of children being tortured) we can find a near uniformity of response-but not even this produces unanimity. Nor is the moral sceptic willing to accept the partial concession that while humans do in part subjectively interpret values, there is nevertheless also some real, external component to values, a concession which seeks to draw an analogy with humans' processing of sensory data like colour, or between ethics and science. Not even the attempt to limit the finding of "rightness" to particular humans in a specified time and place, in effect to make epistemology independent of metaphysics, ${ }^{8}$ succeeds according to the sceptic. Categorical imperatives are, for her, actually hypothetical imperatives fundamentally dependent on the observably variable sentiments and feelings people happen to have and not determined by relations of ideas or a function of external, mind-independent fitnesses.

The form of scepticism I have just traced clearly rejects the existence of objective, or "real" or higher or mind-independent values, attributing to them no non-relative status. It is important, however, to note what this scepticism does not doubt. It does not doubt, as Berkeley purported to do, ${ }^{9}$ the existence of an external, material, causal world. Nor, in a fashion oddly reminiscent of Berkeley, does it extrapolate from literary criticism to the view that humans can know nothing "real" or "objective" of even the external, causal world. ${ }^{10}$ That the natural, causal world exists, with its uniformity of like cause producing like effect, is not doubted by my scepticism. Provided the external world shows a regularity of like

6 We need not concern ourselves here with the extent to which that construction is a product of evolution (of nature) and the extent to which it is one of socialising, education and culture (of nurture).

7 For a telling critique of the secondary qualities analogy see S Blackburn's "Errors and the Phenomenology of Value", chapter one in T Honderich (ed), Morality and Objectivity (Routledge \& Kegan Paul, London \& Boston 1985).

8 An example of this is R Dworkin's "One Right Answer" thesis. See for example Taking Rights Seriously (Duckworth, London, Revised Edition, 1978).

y See G Berkeley, Bishop of Cloyne, The Principles of Human Knowledge ed K Winkler (Indianapolis Hackett Pub, 1982.), in Part I. Berkeley argued that all sensory data were ideas of sense excited in the perceiver's mind by the will of God. A world of material things existing independently of minds was denied, but not a world of other, especially divine, ideas and minds. Solipsism is thereby avoided.

10 This is a strand in the thinking of what is styled as "postmodernism". See, for example, S Fish, Doing What Comes Naturally (Clarendon Press, Oxford, 1989). 
cause being followed by like effect, a regularity of observed events, it is mere bad faith to purport to doubt the existence, the "realness", of the natural, causal world. However much such a world may be filtered and interpreted by humans, none who wishes to go on living is prepared, from whatever culture, sex or socio-economic background, to jump from a seventh storey window or to stop eating. As Hume said, humans are not capable of this kind of doubt; assertions to the contrary are mere pretence. Belief in the existence of causation and of a continuing and distinct external world is a belief we humans cannot escape and anyway would not want to, however precarious or circular or unsatisfying the support for that belief may ultimately prove to be. ${ }^{11}$

The point is that my version of scepticism is not Pyrrhonistic, nihilistic; it does not doubt everything. There are external, imposed criteria for "what the case is" as regards factual consequences in the natural, causal world. In some realms therefore all opinions are not equally valid. The view that the sun will fail to rise tomorrow, for instance, is almost certainly wrong. Where there is an externally imposed regularity there is a right answer, even if that answer may prove to be beyond the grasp of humans (eg humans may never know how to cure AIDS or what the universe was like before the Big Bang).

My version of scepticism then starts from an acceptance of the mind-independent reality of the outer world and the basic uniformity of nature, however unexaminable the core foundations of such a belief may be. I whole-heartedly adopt an empirical, naturalistic programme in which observed data and inductive reasoning become the validating standards. It is on the basis of these standards that I doubt the existence of objective values, of natural law. ${ }^{12}$ The evidence seems to me to be against there being any such "higher", mindindependent values or categorical imperatives.

Are all values then equally valid? The moral sceptic's dilemma appears to be this: To deny objective values is to play the game and admit there are criteria for establishing truth (ie by asserting that scepticism is true and realism false). To refuse to play the game, because all opinions are, if strongly felt, equally valid, is to accept even the view that values are objective. However the dilemma dissolves once one distinguishes empirical criteria from criteria about rightness and wrongness of values and norms. My view is that there are external, imposed criteria for "what the case is" as regards factual consequences. To some

11 This is, in essence, the argument of D Hume in Book I of A Treatise of Human Nature ed L A SelbyBigge, 2nd ed, revised by P H Nidditch, (Oxford University Press, New York, 1978).

12 The sense of "nature" and "natural" is ambiguous, indeed quite variable. Natural can be used as the opposite of the miraculous, or of the rare and unusual, or of that which is due to human artifice. I do not here mean "natural law" where what is natural is being opposed to what is uncommon or miraculous so that "natural law" is being used to describe what usually happens or what, barring supernatural intervention, always happens. By "natural law" I mean here laws or rules which are not the product of human artifice (deliberate or unintentional). 
extent at least the natural, casual world is a given. Torture causes pain and death. Suffering creates sympathy in most people. Scope to be inquisitive and pursue ideas where they lead, often results in happier people and technological advance. The natural, causal world may well be interpreted by people but there is a core level of regularity, of imposed facts, and this can be used as a criterion of truth (at least for as long as those natural, causal facts continue to hold).

This is not true of normative values, says the moral sceptic like me. Once such values are tied ineradicably to the observably variable feelings and sentiments of people there can ultimately be no criteria for "what values are right" - unless it be allegedly universal or near universal, but still contingent, human dispositions. So rejecting the existence of objective values rests on the evidence from the causal world. On this test or criterion moral scepticism is more likely than moral realism says the sceptic. Of course values may seem and may be believed to be real and mind-independent by many or most. But there is no necessary connection between peoples' beliefs and what is actually the case. ${ }^{13}$ Apparently real or objective moral values are but felt and projected sentiments and feelings, says the moral sceptic, which cannot be true or false, right or wrong. One feels them or one does not. They have no propositional content. Hence the dilemma's horns are cut-off simply by explaining that criteria for determining truth do exist regarding the state of affairs in the natural world but do not exist regarding "goodness" or "rightness" in any sense grander than what is observably, normally felt.

One consequence of translating values into a function of human sentiments is that "rightness", to the extent that it has any external or non-subjective element, becomes a shorthand for the sentiments of the majority. Beyond mere majorities though, does experience evince any universal, any unanimous human responses? The moral sceptic, recall, places no small significance on the observed variety, throughout space and time, of moral standards and criteria. Experience does show, when it comes to some very general matters ${ }^{14}$ (like the willingness to look after one's children, the revulsion from watching and hearing intense suffering, or the pleasure involved in hearty laughter) that certain sentiments are very regularly found indeed. There may even be other causal regularities, like the need for rules in order to live in groups larger than the family or the desire to be free from external

13 See R Dworkin, in particular in Law's Empire (Fontana, London, 1986) 76-86. The sceptic need not deny that most people believe values are real or mind-independent. People might generally be in error. The sceptic says the evidence is, on balance, against the existence of such a status for values; he does not say that people have no evaluative sentiments of their own nor that some, many or most might not believe "real", "objective" values lie behind these sentiments.

14 On both the relativity of particulars but the uniformity of a few general matters see David Hume's "A Dialogue" in Enquiries Concerning the Human Understanding ed L A Selby-Bigge, 3rd ed, revised by P H Nidditch (Oxford, Clarendon Press, 1965). 
constraints, which cut across cultures and epochs in certain respects. Whether any of these human sentiments, desires and responses be found in all humans, without exception, I do not presume to say. Certainly finding unanimity about any value or of any response would be extremely difficult. Hence I simply remark that in some basic ways there appears to be great standardisation and uniformity in humans and that this observed uniformity permits the moral sceptic to talk sensibly of "good" and "beneficial" consequences in more than an egoistic sense. "Good" consequences are those that promote, respond to and enhance regularly shared sentiments. Qualities, rules, rights or outcomes can be "good" in this sense on account of their being felt to be useful or agreeable by enough people to pass some test of uniformity.

Notice how far the threat from Pyrrhonism, from extreme relativism, from nihilism has now receded. The natural casual world provides an imposed regularity and hence a basic, however much interpreted, criterion of truth (eg This pen will fall if I open my hand and let it go). Elucidating causal consequences may sometimes resolve disagreement as the likely effects of birth control programmes or aid initiatives or constitutional reforms are explored. Sometimes disagreement will remain, but no longer will it be about moral evaluation (for example whether segregation is wrong) but about likely consequences (for example whether busing leads to a better racial mix in schools or to a flight of whites to private schools), with the advantage that disputes about consequences generally, with time, will be answered. And of course sometimes disagreement will remain, even where the disputants agree on all the likely consequences. For example you and I may hold differing views about China's "one child" policy even though you accept my ominous demographic extrapolations were the policy to be relaxed and even though I accept the policy's attendant high rates of female infanticide and enforced abortions. Different people sometimes simply have different sentiments about what is right and wrong, good and bad, after all the information is known. ${ }^{15}$ For the moral sceptic such cases are not about right and wrong values but about more and less popular sentiments (and, no doubt, about his own particular subjective sentiments). After investigating the potential consequences, after weighing likely outcomes, what better to do, in the light of continued discord, than to make majority sentiments ${ }^{16}$ the final arbiter? ${ }^{17}$ In the end, all that is left to the moral sceptic are consequences and feelings.

15 Compare W B Gallie's "Essentially Contested Concepts", 56 Proceedings of the Aristotelian Society (1965), 167-198.

16 Majority sentiments, be it noted, need not be hostile to the minority. The majority might well prefer to provide protection for minorities in many situations, perhaps fearing that they may one day be in the minority or perhaps simply recoiling from ungenerous behaviour.

17 One could make one's own sentiments the final arbiter of course. J Bentham calls this the principle of "sympathy and antipathy" - I like it or I do not like it - which, he says, is really the absence of all principle. See J Bentham, An Introduction to the Principles of Morals and Legislation 
Such is my conception of moral scepticism. In a paper purporting to be about law, one might well wonder at the space devoted to a conception of morality. But in my view any proper examination of the threat posed to law by scepticism, by the questioning of law's foundations, must start with those foundations. One must take a position in the debate between moral realism ${ }^{18}$ and moral scepticism. In this need to examine morality, (if not on the view of it ultimately taken) I am much of Lon Fuller's mind: ${ }^{19}$

But when law is compared with morality, it seems to be assumed that everyone knows what the second term of the comparison embraces.... In the present case, it has seemed to me, the legal mind generally exhausts itself in thinking about law and is content to leave unexamined the thing to which law is being related and from which it is being distinguished.

\section{SCEPTICISM AND LAW}

Having sketched a version of moral scepticism, one which doubts the existence of any anchor for values beyond the plainly contingent realm of the sentiments people happen to have ${ }^{20}$ I now turn back to law and sceptical challenges to law's authority and effectiveness.

The enterprise "of subjecting human conduct to the guidance and control of general rules" ${ }^{21}$ as I have noted, can be challenged on numerous fronts. Many, the preponderance in fact, of the current challenges can be fairly epitomised as asserting "law is not legitimate". In this sense these challenges can be regarded as being sceptical. But how sceptical are they in my sense, the sense in which moral scepticism rejects the existence of mind-independent values? To answer this one must decide what assumptions lie behind such claims as that "law is not determined by the rules but by arbitrary power shaped by ideology" or that "rules irreconcilably conflict with non-rule standards" or that "the law is never impartially interpreted by male judges" or that "women have different values than men" or that "rights over-emphasise individualism at the expense of the community" or even that "it is the privileging of particular norms, not the rules, which suppresses partial conflict in society".

(Oxford, Clarendon Press, 1879), chapter two.

18 I mean the category "moral realism" to subsume all the various views which accept, on whatever grounds, that values are somehow non-relative and mind-independent.

19 Above n 4, 3-4.

20 Again, I say nothing here about whether those sentiments be caused by evolution, by unplanned convention, by social contract-type agreement, by the stage of development of the economic system, by the dominant class, by the dominant ideology, by religion, by raw power or by some combination of any or all of these.

21 Above $n 5$. 
These claims, and various variations and declensions of them, are of the sort associated with currently popular movements ${ }^{22}$ dissatisfied with the legitimacy of parts, or all, of the Western legal order. At times members of these movements do profess to be sceptical of objective values and answers. ${ }^{23}$ However it is far from obvious that such professions consistently accept the full implications of moral scepticism as I have outlined it in part one above.

One possibility is that adherents of such movements are moral sceptics. I shall consider that possibility, and the implications of moral scepticism, in a moment. The other possibility is that, whatever the adherents' own claims, ${ }^{24}$ they in fact do not reject the existence of mindindependent values. Instead there is simply a different set of values proposed as being the "true" or "real" or "right" ones. Thus "communitarianism" is substituted for "individualism", "consensus" for "confrontation", "non-hierarchical structures" for "hierarchical ones", "standards" for "rules", "female" for "male", "equality" for "freedom" and the list goes on. But the very point of moral scepticism is that all values are relative, subjective, linked to variable and varying human sentiments. In other words the moral sceptic's rejection of the existence of objective values (which is a question of status, of what it is values actually are) tells us nothing whatsoever about her preferred values or political orientation (which is a question of content, of what her own sentiments happen to be). Her scepticism can be linked to any set of preferred values. The same scepticism of the status of values that leads to the dissatisfaction of the Critical Legal Studies or feminist movements, indeed to the corrosive tenets of deconstructionism, leads just as well to the political conservatism of Hume ${ }^{25}$ or Hobbes. ${ }^{26}$

22 At the risk of such a broad generalisation turning to caricature, I would associate the critical legal studies and feminist movements with some or all of these claims. This though is quite obviously a generalisation as there is much disagreement and diversity of viewpoint even within these socalled movements.

23 See for instance Roberto Unger's, "The Critical Legal Studies Movement", (1983) 96 Harvard Law Review 561, 565, and Katharine Bartlett's, "Feminist Legal Methods", (1990) 103 Harvard Law Review 829.

24 Of course one need not take claims at face value. A good analogy can be drawn with judicial decisions. What judges say they are doing, what they think they are doing, and what an impartial observer might think they are doing can all differ.

25 For Hume, the absence of objective values was the main ground for clinging to tradition, to what was known. Conserve existing standards, values and arrangements, he thought, because such criteria are better than nothing. What is already established, accepted as it usually is by the majority, will produce better results than any proposed alternative. Change for Hume, in other words, most wisely proceeded slowly.

26 See Boswell's report of Samuel Johnson's remark that "Hume is a Tory by chance.... If he is anything, he is a Hobbist." For the various sources of this remark. See Paul Russell's "A Hobbist 
What the sceptic cannot do, if he is to remain consistent, is to jettison his sceptical clothing once it has exposed the absence of any "real" basis for existing values and normative beliefs. He cannot then put forward his own equally contingent substitutes without admitting that these new values are just as subjective as those they are meant to replace. Scepticism, having done its job, cannot simply be put safely away to enable a comfortable, familiar return to "rational" models, "right" standards, "true" ideals and "just" outcomes.

The extent to which current challenges to law's legitimacy are guilty of this sin, of implicitly substituting one set of "correct" values and rules for another, varies with the particular advocate and adherent. Most often one is left to read between the lines as no arguments in support of moral scepticism (ie against the existence of mind-independent values), let alone any working out of scepticism's ramifications, are advanced. For instance, will increasing the number of women judges make for a truly neutral judiciary ${ }^{27}$ or simply one with a greater variety of subjective viewpoints? Are non-capitalistic, rotating capital funds $s^{28}$ "just" or simply a different way of financing development with different probable consequences and efficiencies? Are non-liberal, communitarian values any less contingent, any less subjective, or any less based on preference than liberal values? In this paper I do not propose any exegetical analyses of particular works. Rather I merely note this second possibility that behind sceptical claims can lie, latent but implicit, very unsceptical assumptions and modes of thought. Consistency condemns any such latent assumptions.

The other possibility I raised is that sceptical challenges to law are in fact sceptical in the sense outlined in part one of this paper. Let us concentrate, henceforth, on attacks and challenges which are consistent and do rest on some form of moral scepticism. To do so we need next to look at some of the implications of such a consistent scepticism. We will then be better placed to turn back to consider Berman's fear ${ }^{29}$ that the Western legal tradition is threatened by it.

Tory: Johnson on Hume" (1990), 16 Hume Studies 75, 80.

27 See Madam Justice B Wilson's "Will Women Judges Really Make a Difference?", (1990) 28 Osgoode Hall Law Journal 507. See also Sue Davis's "Do Women Judges Speak 'In a Different Voice?'”, (1992-93) 8 Wisconsin Women's Law Journal 143.

28 See Roberto Unger, False Necessity - Anti-necessitarian Social Theory in the Service of Radical Democracy (Cambridge University Press, Cambridge, 1987), in particular from 491.

29. Above $\mathrm{n} 2$ and accompanying text. 


\section{THE IMPLICATIONS OF SCEPTICISM}

What does moral scepticism have to say about rules, rights and indeed that much maligned specimen liberalism? Certainly the sceptic can accept the Hartian description ${ }^{30}$ of a legal system in which a system of rules, some imposing duties (and hence rights ${ }^{31}$ ), some conferring powers, and all ultimately resting on a political foundation, ${ }^{32}$ is seen to be at the heart of law. We can observe that our legal systems are at least in part comprised of differing sorts of rules of general application, albeit of differing levels of specificity and determinacy. Of course we can also observe that rules do not exist in a vacuum; they must operate in the context of background social practices, values and principles. For the sceptic such values are actually projected, subjective sentiments but still they are sentiments shaped by the dynamics of social life. Moreover in a given society and time, there clearly exist majority sentiments, majority values. This too is an observable fact (eg most people in the West today would think it wrong to pay women less than men for doing the same job). ${ }^{33}$ Obviously rules will be interpreted against those background values.

As for whether rules are less indeterminate than these background social values and standards, again the sceptic, resting her answer on the observable evidence, can give a firm answer. "[R]ules of any sort are in their nature apt to be very much more determinate than principles. ${ }^{134}$ But such an assertion need not deny that rules often incorporate non-rule standards or values; they do. ${ }^{35}$ Nor does it deny that even the most specific of rules leaves some penumbra of doubt, some indeterminacy and uncertainty. Indeed in such Hard Cases ${ }^{36}$ the moral sceptic would not hold all disagreement to be merely linguistic or factual but would most definitely expect there sometimes to be real, substantive disagreement because of

30 See H L A Hart, The Concept of Law (Clarendon Press, Oxford, 1961). Hart gives an analysis of a legal system largely from the observer's perspective.

31 As regards rights see $\mathbf{n} 50$ below and the accompanying text.

32 Above n 30, Hart calls this the "Rule of Recognition" and says it is, as a matter of social fact, either accepted (eg people accept that their elected representatives have the final word on economic policy) or is not and there is anarchy or revolution.

33 It might be thought that a more universally shared value would be the undesirability and evilness of having one's own genitals mutilated. Again, however, not even this is true of everyone. See the House of Lords' decision in Rv Brown [1993] 2 WLR 556.

34 N MacCormick, "Reconstruction after Deconstruction: A Response to CLS", (1990) 10 Oxford Journal of Legal Studies 539, 545 The use of this quotation is not meant to imply MacCormick is a sceptic.

35 Hart makes this point himself. See Hart, p. 199. The obvious example is a Bill of Rights. Such legal instruments essentially enumerate a set of moral criteria about the place of the individual in society.

36 I take this well-known term from Dworkin. See above $\mathrm{n} 8$. 
varying and often conflicting individual sentiments and evaluations. Rules serve to rank priorities, limit the scope of argument and focus dispute; ${ }^{37}$ they do not provide comprehensive answers or completely eliminate the interpreter's discretion. Or so says the moral sceptic.

What does the sceptic say of the need for rules in order for people to live together in groups larger than the extended family? The strong Marxist claims that rules are not necessary (or rather will not be necessary once the economic system has been altered so that need is the crucial determinant of what goods are received, exploitation and alienation have been eliminated, and all have basically the same substantive wealth) to social life. ${ }^{38}$ This cannot be tested against experience ${ }^{39}$ which is the one criterion the moral sceptic allows. The sceptic's position, therefore, may be that everything we have so far observed about humans indicates that rules are necessary to social life, together with a greater or lesser agnosticism depending on the extent to which he finds such mooted economic systems unlikely ever to be achieved.

In short the moral sceptic is quite willing to admit that rules neither provide a "right" or "true" or even uniformly agreed upon answer, nor do they eliminate the influence of the interpreter's own background values and preferences. If this is what is meant when it is claimed that interpreting law is a political exercise, the sceptic, my sceptic at any rate, would agree. It does not follow from that, however, that rules are generally no more certain, no more determinate, no more constraining and limiting than non-rule standards and values. They are. Any contrary claim is overwhelmingly implausible, on the evidence to hand.

This is not to say that the moral sceptic rejects all of the radical critique of so-called liberalism. ${ }^{40}$ Dworkin's notion of the "one right answer" ${ }^{\text {"41 }}$ to interpretation would receive short shrift from the moral sceptic. ${ }^{42}$ Judges do have discretion and do make law. Hence the

$37 \quad$ Above n 34, 554 .

38 See for instance H Collins, Marxism and Law (Clarendon Press, Oxford, 1982) 100-115.

39 It cannot be tested because such an economic system has never existed. We do not know, therefore, whether human nature is such that say, rules against personal violence will still be needed. To the claim that all the evidence points towards this being the case my imagined Marxist could perfectly well reply that that is because we have all been shaped by an imperfect economic system.

40 I say a "so-called liberalism" because the very notion of $a$ "liberalism" is a caricature capable of being used as a "straw man".

41 It is difficult to tell whether Dworkin has or has not retreated on this notion in the move from his position in Taking Rights Seriously (above n 8) to Law's Empire (above n 13). It is difficult to tell because Dworkin is ambivalent.

42 See J L Mackie, Persons and Values (Clarendon Press, Oxford, 1985), chapters X and XI. See Also J Allan “A Moral Scpetics Attack on Dworkin" (1997) 26 Anglo American Law Rev 405. 
sceptic would agree that questions about how we ought to distribute social and economic policy-making power, in our world where solutions to partial conflict situations are not "out there" waiting to be found and discovered, ${ }^{43}$ are of crucial importance. She would also dismiss as incoherent the notion of a "morally neutral" state. ${ }^{44}$ A state which values ${ }^{45}$ taking no official view about what religion, if any, is correct or permissible or what political speech is correct or permissible - one in effect, that favours tolerance and diversity - is no more morally neutral than one which does. Taking no position on certain questions of content is just as much a moral position as taking a position. ${ }^{46}$ Dworkin himself, ironically, makes this very point when he talks of internal scepticism being itself a moral position. ${ }^{47}$

This, however, is no threat to my moral sceptic once it is clear that he is sceptical of the status of values - he says none of them is "higher", "real", mind-independent or anything more than projected sentiments. But of course he too has his own sentiments. He too takes a position on content ${ }^{48}$ (eg. that slavery is evil). He too, if he shares my sentiments, may even favour diversity and tolerance. The fact is that being indifferent or disinterested as to the content of evaluations is itself, for a State as much as for a person, a moral position. Presumably such a disinterestedness usually rests on the good consequences one perceives from the state taking no position on such matters.

Having noted that the sceptic would accept parts of the attack on "liberalism", that same sceptic would also ask the obvious rejoinder. Is any other social structure and set of values any better? Does experience reveal any alternatives which, given existing human sentiments and desires, have better consequences? After all, there is nothing inconsistent in a sceptic preferring something (say liberalism) which she admits has a good many shortcomings

43 Notice how frequently Dworkin makes use of the verbs "to find" and "to discover" Above nn 8 and 13.

44 With all due respect to R Dworkin's "Liberalism", chapter 8 of $A$ Matter of Principle (Harvard University Press, Cambridge Mass, 1985) and J Waldron's "Legislation and Moral Neutrality" in R. Goodin and A. Reeve (eds.), Liberal Neutrality (Routledge, New York, 1989) 61-83.

45 I speak loosely here. Obviously States do not have conscious purposes and cannot value anything. The political structures within a State can be such, though, that certain values (for example pluralism, disinterested judging or a high degree of freedom of speech) are favoured. These values are given a high priority.

46 And in my view its attraction rests on (rarely articulated but implicit nonetheless) consequentialist grounds. Experience shows there are good consequences in terms of most people's happiness most of the time when society is structured to allow diversity and to foster tolerance.

47 See Dworkin above n 13, 76 - 86, where Dworkin fails is in asserting that external scepticism necessarily collapses into internal scepticism. See also above note 42 .

48 J L Mackie, above $n 42$ chapter XI, in particular 147. 
provided she sees no better alternative on offer. By her nature the sceptic looks to consequences and sees values in relative terms. Purportedly ideal value systems not only rest just as much on contingent, subjective preferences as all others, they may not, in practice, be achievable or turn out as expected. In a world of conflicting preferences, differing needs, limited resources, and finite human capabilities, the sceptic will be slow to turn away from what experience shows to be the best on offer to date.

It is on the topic of rights, however, where the implications of scepticism are most stark. On a formal level, as most everyone is these days aware, the existence of a right presupposes the existence of a rule. Alternatively put, the existence of a right is the existence of a rule. ${ }^{49}$ Thus to the query, "where do rights come from?" the answer is straightforward "from a rule which imposes obligations on others (be they individuals, groups or institutions)." In the case of legal rights then, the rules are there for all to see. They can be found in a statute, extracted from a line of cases, seen to have grown up from customary practices, or set out broadly and generally in a Bill of Rights for the judiciary to make more certain, specific and clear (indeed to alter over time) as various cases arise. Therefore to the extent that rules exist in some legal form or other, the origin of the corresponding rights causes no difficulty for the sceptic.

Where there is much difficulty for the sceptic, though, is in the case of non-legal rights (or less exactly but more popularly put, "human rights" or "natural law rights"). Notice, firstly, that having moved outside the realm of legal rights and legal rules, the correlative explanation of rights is of little value. ${ }^{50}$ That the existence of a non-legal or moral right requires the existence of a non-legal or moral rule merely shifts the focus slightly but tells us nothing of from where these non-legal rules might originate. Whereas the moral realist at this juncture can respond by pointing to mind-independent fitnesses or God's prescripts or the fruits of reason or "right" interpretations, the moral sceptic has already rejected such responses as untenable. For the sceptic, non-legal rights do not exist from any perspective that insists on their being linked to "true", "real" statuses or objective senses.

Is that all the moral sceptic can say then, that non-legal rights (eg to free speech in Burma or not to be enslaved in classical antiquity or to a job in the developed world) simply do not exist? Not quite. I think the moral sceptic can actually say something more than this about non-legal rights. While the essence of his sceptical views means there cannot be solid, tangible, non-legal rights in the same way there are solid, tangible, legal rights, there still might be varying moral standards or moral criteria which do in fact emerge in particular

49 For the correlative nature of rights see W N Hohfeld, Fundamental Legal Conceptions as Applied In Iudicial Reasoning (Yale University Press, New Haven Conn, 1919; Reprinted 1964).

50 N MacCormick makes this point in Legal Rights and Social Democracy (Clarendon, Oxford 1982), 144. 
places and times and which then are generally regarded (ie in terms of majority sentiments) as setting acceptable limits on conduct. Consequently the sceptic certainly must start by conceding that such values as protections for free speech, bodily security, or due process, or entitlements to work or to economic development, or even a basic demand for impartiality, are, in the absence of enforceable laws, mere contingent preferences at core. They are for him, at base, ineluctably linked to the responses of human beings - which could conceivably always have been otherwise.

Yet as fragile for some as such a basis may be on which to ground the moral standards which establish moral, non-legal rights, I think at a very practical level one can simply shrug one's shoulders and press on with the task of seeing which values are, or strictly speaking happen to be, widely held. This may require an admission of a rather unfortunate state of affairs. Who would not be attracted by the prospect of values, standards, and rules which are "real" and "right" and awaiting discovery in some Mosaic revelation or presumed as some Kantian major premise or teased out by recourse to some Dworkinian interpretive technique?

But for those people, like the moral sceptic, who find the empirical evidence indicates otherwise, and points away from there being any mind-independent values, there nevertheless remains the fact that certain feelings (say, against the use of torture) are held by most ${ }^{51}$ people today in most, if not all, places in the world. These feelings do, in an amorphous and inexact way, give rise to expectations, standards and entitlements. If some unrepresentative government somewhere were to contravene the standards embodied in such feelings, one could, I think, talk not unwarrantedly of the infringement of a non-legal right. Indeed anytime there is extensive convergence regarding what is acceptable conduct someone could be said, in one sense, to have a right - even where it is not enshrined in positive law; indeed even where it is systematically contravened.

This explicit linking of non-legal rights and moral standards to the contingent responses, sentiments and feelings of human beings seems to me to be the most that a sceptic can do. That may appear to be quite ethereal and insubstantial to some; to be a very weak branch on which to place any weight; indeed, to be a shifting, empty and, for many, unsatisfying basis on which to rest claims for non-legal rights. Beyond merely saying that, unfortunate or not, this is all that actually can be said for non-legal rights, the sceptic would also point out that any conception of non-legal rights still leaves their rights as ineffective tools. By that he refers to the close connection between enforceability and the practical value of rights. ${ }^{52}$

51 However, I have noted above the difficulty in finding universal sentiments or responses in human nature.

52 For a similar view see J Bentham's Anarchical Fallacies (in volume ii of Works of Jeremy Bentham, ed John Bowring, Edinburgh, 1838-1843) or A V Dicey's The Law of the Constitution ed E C S Wade, 
Whether non-legal, moral rights be mere wisps of mutating human sentiments or some absolute, eternal, true and right relations dictating correct conduct is of little significance to the Burmese student who cannot speak her mind or to the American labourer who wants to work but cannot find a job. Unless moral, non-legal rights be made legal, and more importantly enforceable, then to some extent the profound theoretical disagreements between sceptic and non-sceptic are of little practical importance.

Enough has now been said about scepticism and its ramifications to consider whether it poses any challenge or threat to the Western legal tradition.

\section{ANY THREAT?}

I have already noted that wherever large groups of people have lived together there have been rules. Given this causal connection, and provided, like the vast majority, one prefers social life to monastic isolation, it is apparent that law can be of great benefit. Of course, law can also be abused by the world's Hitlers and Stalins. But then since the discovery of fire, it too has been abused. That does not mean that fire, or law, has not been of benefit, or that humans would be better off without it.

I have also suggested that the "liberal" values infusing the Western legal tradition and in which it operates might well be attractive to the sceptic. Ultimately that will depend on the sceptic's own sentiments and his calculation of whether any competing set of values is likely to have better consequences. The point is, though, that there is no necessary connection between moral scepticism and a rejection of liberal values. Any sceptical attack on a particular set of values rests on sentiment and extrapolations of experience.

Where does that leave the question this paper set out to clarify and answer of whether moral scepticism poses any threat or challenge to the Western legal tradition? Perhaps we are now in a position to pose this alternative hypothetical question: "What would happen if the majority of people came to be of the view that mind-independent, objective values do not exist?" I put the problem in this way to eliminate a certain ambiguity in Berman's fear that our legal tradition is threatened by scepticism. Is the fear that more and more people are in fact rejecting as untrue the "... belief in the existence of a body of law beyond the law of the highest political authority, once called divine law, then natural law, and recently human rights" ${ }^{53}$ Or is the fear that moral scepticism, once widely subscribed to, necessarily weakens law's effectiveness, its ability to constrain certain conduct, to promote social cohesion and "civilised" behaviour, and to be a unifying social force?

20th ed (London, Macmillan, 1959).

53 Above n 2, 45. 
These two queries are distinct. The former is analogous to asking whether most people today do reject the existence of a benevolent, personal God. In theory at least it can be answered by surveying people and determining their beliefs. It is about human attitudes. The latter is analogous to asking whether, if people did reject God's existence, bad consequences would follow. That is a question of calculating likely consequences in the light of a certain set of facts existing. But of course those facts may not exist or be likely ever to exist. It may be that most people do not reject God's existence, and it may be likely the majority never will. Similarly, it may be that most people do not now reject the existence of mind-independent, objective values. If Berman's apprehension were merely this, that scepticism is becoming ever more widely accepted and now does, or soon will, predominate, we could conduct research into prevailing attitudes and, perhaps, come to some conclusion. My own view is certainly that this is not the case. The vast majority of people in the West ${ }^{54}$ do not today reject, rather they accept, the existence of mind-independent values. I think, that is, that most people, implicitly or explicitly, are moral realists. The burgeoning tendency of virtually all political discourse to be conducted in the unqualified language of rights supports that view. So does one's experience of what one takes to be the beliefs of most others. ${ }^{55}$ Moral scepticism remains a minority viewpoint. Berman's fear, if this it were, was greatly exaggerated in my opinion.

However, whatever one's views about the former query, it may be more sensible to treat the latter query first. The atheist may think it unlikely that theistic views will ever be displaced as the majority viewpoint and yet assert that a widespread atheism would not lead to moral disorder, chaos or crises. If that assertion be convincing, much of the sting and perhaps some of the point - of the former query would have been drawn. Analogously, if the probable ramifications of a widespread acceptance of moral scepticism be not undesirable (let alone apocalyptic) then any interest in how many in society do or will accept scepticism must rest on something other than a fear of its ramifications, of it being a threat or challenge. Thus, let us consider whether social cohesion is likely to be weakened and a key constraint on conduct unbounded if the background values in which law operates were seen to be nothing more than subjective sentiments. What would the consequences be if morality's "objectified" overlay were stripped away?

54 And more so in the Islamic world, I suspect.

55 There is great difficulty, however, proving what most people believe about values. The difficulty lies in the fact that the conceptual analysis of the structure and usage of language leaves open various possibilities. (Compare Blackburn, above $n$, and his quasi-realist theory of meaning, for example.) Where the use of language is compatible with both a realist meaning as well as other meanings like quasi-realism or ideal observer analyses then conceptual analysis cannot resolve the dispute. I think the matter must then be resolved by experience, by what one thinks others generally mean. Obviously this is a fertile ground for disagreement. 
This is tantamount to asking whether it would be consequentially wise to expose the "fiction" ${ }^{56}$ For one thing, if people are deluded in their belief in the existence of objective values, and if they come to shake off those delusions, will they not see the hopelessness of commanding others' agreement and approval by means of peaceful persuasion and debate? Might not reliance on propaganda, indoctrination and worse, brute force, be then but a small step away? Might not "rational" argument and debate be forsaken in favour of a "ruthless decision to cut the cackle, to damn the heretics and to exterminate the unwanted"? ${ }^{57}$ This objection, in essence, is that were moral scepticism to replace moral realism and become widely accepted, the world would be a much less tolerant place than it is now. ${ }^{58}$ Changes in our Western legal tradition would surely result.

This (purely consequentialist) objection, however, fails to persuade me It relies on a determination of likely consequences which dubiously assumes that the sole motive for employing debate and argument is the prospect of converting others, which presumes that sentiments are less easily re-directed than some purported faculty capable of discovering rightness. It also makes unwarrantedly apocalyptic predictions of people's behaviour in a world in which values are recognised to be dependent on nothing more than sentiment.

It is true that scepticism can be charged with inducing an awareness of the central role of non-propositional feelings. That awareness will, no doubt, lead people in certain circumstances to defend their own interests against those of others through action not words. But let us be clear about this. Egregious anti-social behaviour requires action on any moral premises or view. A complete tolerance which merged into an absolute laissezfaire would produce a society so lacking in cohesion it would probably not last long. At some point tolerance becomes mere weakness. The hatemongering neo-Nazi no less than the psychopathic rapist, for instance, is not to be tolerated but restrained. Hence it is something short of a thorough-going libertarianism that I would prefer, and I suspect most others would prefer including moral realists. Why then should the attainment of a desirable level of tolerance in society be more difficult (or even impossible) with an awareness of the absence of any real, objective values?

I have been quite adamant, do not forget, that the natural, causal world is mindindependent and imposed. My version of scepticism accepts this; it is the possibility of other knowable realms that it doubts. In this causal realm moreover, reason's role is large for it is

56 The belief in objective values is a fiction from the point of view of the sceptic.

57 Gallie, above n 15, 194.

58 This very argument about its greater tendency to foster tolerance was advanced on behalf of moral realism by Thomas Nagel in the course of his 1993 Li Ka Shing Public Lecture, March 18th, 1993 at the University of Hong Kong. 
reason which notes patterns and attempts to predict consequences. Hence argument, debate and persuasion about likely consequences are not foreclosed to the sceptic. Rather, as I have hinted, ${ }^{59}$ a greater focusing on consequences, on trying to discern the complex causes of effects and then extrapolating, would seem quite suited to the sceptic. And so she will note not only the ultimate contingency of values but also the historical consequences of intolerance - the limits it will eventually place on one's own scope for action, the fear, the hypocrisy and the rest. Hence not only is it a major distortion to say that moral scepticism precludes or impedes argument, it is far from clear that a weighing up of consequences evidently tilts the calculation of self-interest towards intolerance over tolerance. This is even more the case for those with a friendly disposition or love of argument. Meanwhile scepticism's emphasis on what can be debated and argued about, as regards consequences, might well end up raising the level of argument, debate and policy-making.

The sceptic has a further reply too. It is to take the offensive. While the moral realist's case for his own greater tolerance rests on an alleged need for reason to mediate the passions, ${ }^{60}$ to be there to withstand the onslaught of darker forces, that case completely ignores the effects of believing in single right, real, objective values. Does this belief increase tolerance? Few people who "know" there are objectively correct wrongs and rights doubt that those wrongs and rights are the same as their own subjective perceptions of them. Such people must find tolerance of widely diverging views next to impossible to sustain. Their converting dissenters should warrant not blame but praise, even from the converted. At best such moral realists might be able to don a Kiplingesque mask of noblesse oblige, a willingness or felt duty to suffer the follies of the blind and inferior. But that mask takes much effort to keep on, as so much of history has shown. Nor is that Kiplingesque quality what I mean by tolerance. I mean a level of forbearance borne of recognising that competing preferences and sentiments - albeit not calculations of likely consequences - are as valid and as much to be expected, and in most situations accepted, as one's own. This is the tolerance of one who sees that his own proclivities might not have been what they are and that the adamant, self-righteous insistence on "correct" attitudes ultimately is founded not on solid, higher absolutes but on malleable, contingent - and rarely universal - human sentiments. In short, tolerance of this sort, the avoidance of neo-Puritanism, is if anything easier for the sceptic. Contrary to this moral realist's objection then, I think tolerance would flourish and prosper at least as well in a community of sceptics as it has amongst moral realists. But then that is not to set too high a test.

59 See $\mathrm{nn}$ 15-17 and accompanying text.

so See Plato's Republic (Indianapolis, Hackett, 1974) inter alia. It is a part of the case for moral scepticism, one not examined here, that reason is inert and can neither move action nor, alone, control sentiments. See Book I of Hume, above n 11. 
Succumbing to the temptation to advance a consequentialist argument ${ }^{61}$ does not serve the moral realist very well either. It amounts to maintaining that even if moral scepticism be in all likelihood factually accurate and true we should disavow it for its undesirable effects. This sort of Benthamic utilitarianism sits oddly beside an attachment to real, true values. The realist's "optimism" that the world has inherent, imposed values has suddenly, and quietly, given way to a "pessimism" about whether good consequences will align with truth.

But if not by portending a breakdown of tolerance, does exposing the fiction pose some other risk? This fear cannot be lightly dismissed. The moral overlay of "right" conduct and owed "duty" may provide an immediate support to a system of constraints on individual conduct that calculations of long-term self-interest cannot, or rather does not. Hobbes and Hume seem to me certainly to be correct in thinking that having a system of constraints on action does produce much better consequences (given most people's preferences) than not having one. We need look no further than Bosnia or Rwanda to see that. But calculations of self-interest, and here I side with Hume, tend not to be distinctly long-term. Unmasking morality as merely a way of easing, however desirable that easing be, the effects of inevitable partial conflict in society may let loose a bevy of short-term calculators or increase the number of society's free-riders. The question is whether humans who believe certain conduct has a mind-independent rightness about it are better able to constrain their conduct than those who simply see the long-term benefits of such constraints. I do not know the answer. One's opinion seems to depend upon how optimistic about people one is. But whatever the answer to that, it seems true that the moral overlay, the fiction that values have a mind-independent rightness, is not a good thing for everyone. Those at the bottom of the social heap, for instance, tend to get locked in because "the adding of moral overtones to [a reciprocal practice of constraints on conduct] will in general have a conservative tendency." ${ }^{\prime \prime 2}$ But equally, the moral overlay may lead the strong to postpone making too great a use of their dominant position. ${ }^{63}$ So again, it is difficult to predict whether good consequences will align with truth (ie exposing the fiction).

The related question of whether an absence of apparently external constraints on action will place too great a burden on law seems easier to answer. Even if non-legal (and hence not officially sanctioned) constraints on conduct became less effective, there is little evidence that official, organised constraints and sanctions could not do the job. The fear though, and perhaps this was Berman's fear, is that to continue to do the job the Western legal tradition would have to change, perhaps drastically. Whether well-founded or not,

61 That is that moral realism has better consequences, in respect of greater tolerance, than scepticism.

62 J L Mackie, Hume's Moral Theory (Routledge, London, 1980) 154.

63 Above n 62, 155. 
this fear is quite different from vague, nebulous complaints that "law is not legitimate". As legitimacy is itself an evaluative notion, and as the sceptic sees all evaluation as ultimately subjective, she would expect some dissatisfaction at the outcome of all partial conflict resolution. Besides, the sceptic's talk of no objective values and hence no mandated outcomes or distributions is no more suitabie (indeed in a world where most are moral realists it is less suited) to the complaints of society's "losers" than is natural law or human rights terminology. The cry of "illegitimacy" is an implicit plea for a different outcome and set of values, not a comment on the ethereal and insubstantial nature of values. As for matters of content, at least the process of legislation through negotiation and compromise, with majority opinion as the final arbiter, offers hope to sceptic and non-sceptic alike that great social conflicts over substantive distribution might be averted.

\section{CONCLUSION}

Moral scepticism need pose no challenge to the Western legal tradition. It is compatible with the most thorough-going traditional conservatism as well as with radical dissatisfaction. Nor is the sceptic likely to reject the benefits of law or even of the preponderance of those values that surround it. Certainly tolerance is every bit as likely to prosper amongst sceptics as amongst realists. In addition, scepticism has the advantage of tending to focus on consequences in the external world, where there are imposed criteria and right answers for what is likely to happen. How great the threat from scepticism is depends largely on how useful it is for moral constraints to be perceived as external to people (the way law is external to people). That is no easy matter to decide. Certainly the recent decline in religious belief in the West has not led to catastrophic results. But then perhaps that is because one "external" constraint has been replaced by another. Morality, after all, is still widely seen as external, real and objective. And that, in my view, is unlikely to change in the foreseeable future. If it did though, the likely consequences seem closely connected to the view one takes of people generally. With a little optimism and a more or less happy temperament one could say that scepticism does not divert us from the road we are presently on. The road is the same; it is the map that has changed. But nothing of content is wholly lost or gone. 